\title{
HUMAN OR MACHINE? A STUDY OF ANTHROPOMORPHISM THROUGH AN AFFORDANCE LENS
}

\author{
Dana Lunberry ${ }^{[0000-0002-8014-296 X]}$ and Jonathan Liebenau ${ }^{[0000-0001-6536-6319]}$ \\ London School of Economics, London, UK
}

\begin{abstract}
Anthropomorphism- the tendency of humans to apply human-like attributes to non-human objects- has received growing attention by scholars across multiple disciplines. With increasing popularity of service and personal robotics and conversational agents, scholars of information systems have begun to shed light on some of the technology features and processes related to anthropomorphism. This study applies a socio-technical approach using affordance theory to examine the relationship between technology and anthropomorphic perceptions among users. Evidence is gathered from an empirical study involving the introduction of interactive voice response (IVR) with savings clients of a savings and loans company in Ghana. The findings highlight four main ways that the IVR technology exhibited human-like qualities within the user-technology interaction (as perceived by users). This paper illustrates how a study on the relationship between technology and anthropomorphism might be conducted through an affordance perspective. It also offers implications for technology development.
\end{abstract}

Keywords: Anthropomorphism, Technology Affordances, Interactive Voice Response, Financial Services.

\section{Introduction}

Affordances, or "potentials for action"[1], can be employed as a conceptual tool for examining the link between technology and anthropomorphic perceptions of users. Anthropomorphism refers to the tendencies of humans to apply human-like attributes to non-human objects. Anthropomorphism as a psychological concept is becoming increasingly relevant in the field of information systems (IS) with the rise of human-like robots (often referred to as "humanoids") and conversational agents such as voice assistants and chatbots. As more organizations digitize the customer-institution interface, human-to-human interactions are being replaced by human-computer interactions which use natural learning processing, artificial intelligence, and machine learning to mimic human-to-human communication [2].

Until now, anthropomorphism has largely been studied as psychophysiological processes [3-5] but the literature outside of psychology and behavioral studies is growing and is shedding light on other related processes. In IS and especially the field of robotics, the literature has begun to shed light on the technology processes involved in 
anthropomorphism and its implications for technology design and diffusion [6]. Key examples include Tondu (2012), Iossifidis et al. (2004), Schuetzler et al. (2018), Taddeucci et al. (2002), and Hashimoto et al. (2002). In 2012, Tondu (p. 612) introduced the term "technical anthropomorphism" to refer to the technological artefact which results from the human-machine mimicking process.

In IS literature, anthropomorphism has been recognized for playing a key role in helping technologies adapt to human society, which in turn helps humans adopt these technologies as users [7,11]. By developing technologies to mimic human-like attributes, these technologies afford increased familiarity for humans which helps facilitate the user adoption process. This paper builds on the existing IS literature and examines anthropomorphism in the adoption of a new technology by users in the context of financial services in Ghana. Using an empirical study, we employ an affordance lens to examine aspects of the technology and the socio-technical relationships which help facilitate anthropomorphic perceptions among users. In doing so, we shed light on some of the most conceptually important issues of today's digital age which are located at the core of technology design, diffusion and adoption.

We start with the theoretical underpinnings of the research on technology affordances and summarize the existing affordance literature in IS. Next, we describe our research methodology, describing our case study and research methods. We then present our findings, showing how and in what ways IVR exhibited human-like qualities as perceived by users from a socio-technical perspective. Lastly, we discuss the findings and their implications for scholarship and practice. We argue that affordances as a conceptual framework offers an improved understanding of the socio-technical relationship related to anthropomorphic outcomes.

\section{Affordances as a Conceptual Framework}

Affordance theory originated from James J. Gibson's work $(1979,1986)$ in the field of ecological psychology. Gibson conceptualized an affordance as a link between an organism and its environment. "The affordances of the environment are what it offers the animal, what it provides or furnishes, either for good or ill" (Gibson, 1986, p. 127). Gibson conceptualized affordances as phenomenal in nature and not as physical properties. Affordances are not properties of the organism nor the environment. Instead, they are relational and are situated within an interaction. They are a direct link between perception and action and can be conceptualized as "action possibilities" (ibid).

The affordance literature in IS has grown substantially in the last decade (i.e., Anderson \& Robey, 2017; Leonardi, 2011, 2013; Majchrzak \& Markus, 2012; Majchrzak, Markus, \& Wareham, 2016; Markus \& Silver, 2008; Robey, Anderson, \& Raymond, 2013; Seidel, Recker, \& Brocke, 2013; Strong et al., 2014; Volkoff \& Strong, 2013; Yoo, Boland, Lyytinen, \& Majchrzak, 2012). Within IS, the term affordance has become a concept that broadly encapsulates the relationship between technology and its users but no single conceptualization of affordances dominates the literature. While IS scholars tend to agree that the concept of affordances is useful for examining socio-technical phenomena, Stendal, Thapa, and Lanamaki (2016) highlight 
the lack of consistency among scholars around whether affordances are intended or emergent, functional or non-functional, and potential or actual.

In addition to IS, various disciplines including psychology and design fields, humancomputer interaction (HCI), organizational studies, and communications and media studies have used (and expanded) upon affordance theory, making the conceptualization of affordances suit various research needs and contexts. In communications and media studies, Nagy and Neff (2015) have introduced the term "imagined affordances" to underscore the importance of the imagination in affordances, which they state are located somewhere between the technology and human actors amongst expectations, intentions, perceptions, attitudes, and actions. Nagy and Neff (2015) argue that imagined affordances provide users with agency.

Following Gibson, Nagy and Neff, and the work of many other scholars, this research applies affordances as a multi-faceted concept that highlights the critical role of user perception within the socio-technical relationship. User perception is critical to technology development and technology-related outcomes. According to Kardes, Cronley, and Cline (2015; p. 100), "understanding perception and how it influences consumers' attention to the environment, their interpretation and comprehension of stimuli, and ultimately their behavior, are essential to developing successful products and marketing messages." Hence, an affordance lens - which focuses on the sociotechnical relationship and user perceptions - provides a particularly suitable tool for carrying out research on technology and anthropomorphism.

\section{$3 \quad$ Methodology}

\subsection{Case Study}

This research uses an empirical case involving a pilot project that introduced interactive voice response (IVR) with financial savings clients of a large savings and loans company in Ghana ("ABC Company"). The research examines ways in which the IVR technology exhibits human-like qualities for the user-technology interaction. IVR is a computerized phone system that enables organizations to send pre-recorded voice messages via mobile phone and to receive responses from listeners typically through voice applications or by typed commands on a phone keypad.

The pilot project took place over an 11-month period in 2017-2018 and targeted 46,671 clients of the institution (nearly $10 \%$ of the institutions' existing clientele). In total, 23 IVR messages were sent to clients ("users") during the project period, at a rate of one message per week on average. While most messages were focused on the topic of savings, five of the messages contained other content such as information about the project and holiday greetings. The messages that were savings-related gave basic information on savings such as tips on how and when to save, how to develop positive savings habits, and the importance of savings and goalsetting. Some messages provided information about the institutions' savings products, such as types of savings accounts and channels for making savings deposits. The content aimed to associate savings with positive outcomes for people's wellbeing by framing savings as a safety net for times 
of emergency, a good way to cover familial expenses such as school fees and retirement, and an aid for fulfilling life ambitions.

Some of the messages responded to recent activity in the users' savings accounts. For example, if balances increased, these users received a congratulatory message and were encouraged to continue saving regularly. If balances declined, these users received a message that encouraged them to make small yet regular efforts to increase their balances.

Some of the calls were used to collect information from clients through IVR surveys known as prompts. The following provides an example of a prompt:

Hello valued customer, this is Alice again, from ABC Company. We have noticed that your savings account at ABC Company has stayed at a low balance. Can you tell me why you haven't been saving?

Press 1 if you save somewhere else.

Press 2 if you save at home.

Press 3 if you have no excess money to save.

(A different voice: Once you press 1, 2 or 3, listen again to hear what Alice wants to tell you. Would you like to re-listen to this message? If yes, press 0.)

As illustrated by this example, users were able to interact with the institution through IVR in two main ways. First, users could respond to a message using the keypad on their mobile phone handset. Around $30 \%$ of the calls requested a response such as, "press 1 if..., press 2 if...." and every call allowed the user to relisten to the message by pressing 0 . The IVR system was limited to typed commands and lacked the voice capability which some other IVR systems offer. The second way users could interact with the institution was by calling the IVR system back using the same number that been used to call them. This elicited a callback feature so that the users would be atomically called by the system, allowing users to hear the IVR messages at no-cost (as opposed to being charged for the cost of sending a call).

Nearly all the messages were scripted as being delivered by the same character with the name "Alice." Throughout the project, the same voice actors were used for the voice recordings so that users receiving the messages would become familiar with the same voice for "Alice." Multiple voice actors were employed since the messages were recorded into four commonly spoken languages in Ghana (Ga, Twi, and Dagbani) following a translation process. An audio menu was used during the calls to allow listeners to select their preferred language for all future calls.

\subsection{Methods of Data Collection and Analysis}

Data was collected using participant observations and key informant interviews. Participant observations were gathered by the lead researcher who worked alongside the project team for a period of over one year to gain a deep understanding of the IVR system. Observations of the technology artefact, design, and processes were recorded in observation memos throughout the project period. Interviews were conducted at two intervals, mid-project and end-of-project, to collect user perceptions. The interviews 
were conducted with $154 \mathrm{key}$ informants consisting of 102 users (clients) and 52 branch staff. The methods included staff interviews because staff also listened to the IVR messages and were responsible for collecting client feedback. To ensure proportional representation of various savings and call behaviors, cluster sampling was used to select the users for interviews, while random sampling was used to select the branch staff. The interviews enabled the researchers to collect perceptions related to the IVR calls and to understand if and how users experienced human-like qualities through the IVR system. The interviews were conducted by phone and in the local languages of the informants. The interview responses were translated and recorded in English.

The observation memos and transcribed interviews were analyzed using NVivo software. Thematic analysis following Miles and Huberman (1994) was applied to identify human-like factors perceived by users. In total, human-like factors of the technology were identified using 24 unique codes which were descriptive and interpretive in nature (i.e., Alice as memorable, Alice as monitor of past behavior, Alice doesn't listen). Based on patterns among the codes, we categorized these codes into seven meta-codes (such as Alice as caller, Alice as staff member, etc.). These meta-codes were inferential in nature and sought to explain how and in what ways IVR exhibited human-like qualities as perceived by the users. The code hierarchy was established through an iterative process and evolved over time following periods of reflection.

Following this coding process, we applied the analytical tools of pattern matching and explanation building [29] to understand the roles of technology as they related to the codes (the human-like factors). From this analysis, we identified patterns in the relationship between the human-like factors and the technology artefact, design, and processes. Once identified, these patterns helped explain how various affordances of the technology played a role in enabling anthropomorphism as identified in our case.

\section{The Alice Effect and the Technology Behind It}

It is useful to summarize the anthropomorphic perceptions which we found in our dataset before we elaborate on the key technical aspects of our analysis to explain how the IVR technology exhibits human-like qualities for the user-technology interaction.

\subsection{Anthropomorphic Perceptions}

The IVR system was designed to deliver a series of pre-recorded phone calls from a voice self-identified as "Alice." While the name "Alice" was created by the IVR project team as a fictitious character who delivered the IVR messages, evidence in our data showed that "Alice" was perceived and talked about by both clients and staff as if "Alice" were a real person. Various types of anthropomorphic perceptions of "Alice" were found in the data. We categorized the anthropomorphic perceptions into seven main classifications based on inferred identities being attributed to "Alice," which are: 1 . caller, 2. staff member, 3. monitor, 4. conversationalist, 5. talker, 6. instigator of action, and 7. gendered (i.e., mysterious female caller, homewrecker, etc.). Jointly, we call these seven classifications of anthropomorphism the "Alice effect." 
Table 1. The Alice effect: classifications of anthropomorphism

\begin{tabular}{|c|c|c|}
\hline Meta-Codes \& Descriptions & Codes & Examples from the Data \\
\hline $\begin{array}{l}\text { 1. Alice as (Regular) Caller } \\
\text { Alice was referred to by clients } \\
\text { and staff as the deliverer of the } \\
\text { messages. Alice made it easy for } \\
\text { people to differentiate the IVR } \\
\text { calls from other calls that they } \\
\text { may have received from the organ- } \\
\text { ization. }\end{array}$ & $\begin{array}{l}\text { - Message de- } \\
\text { liverer } \\
\text { - Familiar } \\
\text { - Recognizable } \\
\text { - Memorable } \\
\text { - Distinct part } \\
\text { of the call }\end{array}$ & $\begin{array}{l}\text { - "The client said she } \\
\text { didn't remember the } \\
\text { message but when I men- } \\
\text { tioned Alice's name she } \\
\text { said she remembered." - } \\
\text { Staff } \\
\text { - "There were times I } \\
\text { didn't pick [up] Alice's } \\
\text { call." - Client }\end{array}$ \\
\hline $\begin{array}{l}\text { 2. Alice as (Mysterious) Staff } \\
\text { Member } \\
\text { Clients and staff asked who Alice } \\
\text { was and where she was located. } \\
\text { Clients came to the branch looking } \\
\text { for Alice. Clients and staff would } \\
\text { describe the calls as being sent } \\
\text { from a staff member and typically } \\
\text { from someone based at the head } \\
\text { office. }\end{array}$ & $\begin{array}{l}\text { - Looking for } \\
\text { Alice } \\
\text { - Who is Alice } \\
\text { - Where is Al- } \\
\text { ice } \\
\text { - Someone from } \\
\text { the head office } \\
\text { - A staff mem- } \\
\text { ber }\end{array}$ & $\begin{array}{l}\text { - "People asked, 'who is } \\
\text { Alice?", - Staff } \\
\text { - "I went to the branch } \\
\text { looking for Alice. I was } \\
\text { told Alice was in the } \\
\text { head office." - Client } \\
\text { - "There's a teller at Ta- } \\
\text { male named Alice so the } \\
\text { clients thought it was } \\
\text { her." - Staff }\end{array}$ \\
\hline $\begin{array}{l}\text { 3. Alice as Monitor } \\
\text { Clients talked about Alice as } \\
\text { someone who could observe their } \\
\text { financial behavior and would } \\
\text { check in on them. }\end{array}$ & $\begin{array}{l}\text { - Monitor of } \\
\text { past behavior } \\
\text { - Monitor of fu- } \\
\text { ture behavior }\end{array}$ & $\begin{array}{l}\text { - "Alice said it's been a } \\
\text { long time since I visited } \\
\text { the bank to deposit sav- } \\
\text { ings." - Client } \\
\text { - "I have finished paying } \\
\text { for the car so now Alice } \\
\text { will see me saving } \\
\text { more." - Client }\end{array}$ \\
\hline $\begin{array}{l}\text { 4. Alice as Conversationalist } \\
\text { Clients talked about Alice as } \\
\text { someone who engaged in a con- } \\
\text { versation with them. Some clients } \\
\text { described the conversations as } \\
\text { two-way, as if Alice asked them } \\
\text { questions (including questions not } \\
\text { scripted in the IVR messages). }\end{array}$ & $\begin{array}{l}\text { - Asks how the } \\
\text { client was do- } \\
\text { ing } \\
\text { - Greets } \\
\text { - Informs } \\
\text { - Advises } \\
\text { - Joins in a con- } \\
\text { versation }\end{array}$ & $\begin{array}{l}\text { - "One of my clients...her } \\
\text { account was dormant. } \\
\text { Her daughter had passed } \\
\text { away so she had stopped } \\
\text { saving. Alice asked her } \\
\text { what is happening, how } \\
\text { is her business, said that } \\
\text { she should come back." - } \\
\text { Staff } \\
\text { - "Whenever Alice calls, } \\
\text { she greets me." - Client } \\
\text { - "He said it<the call> was } \\
\text { questions about his }\end{array}$ \\
\hline
\end{tabular}




\begin{tabular}{|c|c|c|}
\hline & & $\begin{array}{l}\text { business, how he was do- } \\
\text { ing, an advice to him." } \\
\text { Staff }\end{array}$ \\
\hline $\begin{array}{l}\text { 5. Alice as Talker } \\
\text { According to staff, clients talked } \\
\text { about Alice as talking and not lis- } \\
\text { tening to them nor engaging in a } \\
\text { two-way conversation. }\end{array}$ & $\begin{array}{l}\text { - Doesn't listen } \\
\text { - Client unable } \\
\text { to respond }\end{array}$ & $\begin{array}{l}\text { - "The client wanted to } \\
\text { know who Alice was and } \\
\text { complained that they } \\
\text { wanted to talk back. It } \\
\text { means they didn't know } \\
\text { it was a recording." - } \\
\text { Staff } \\
\text { " "Clients want to interact } \\
\text { with Alice. A common } \\
\text { complaint is that she just } \\
\text { talks and talks and won't } \\
\text { listen." - Staff }\end{array}$ \\
\hline $\begin{array}{l}\text { 6. Alice as Instigator of Action } \\
\text { According to staff, clients talked } \\
\text { about Alice as asking them to do } \\
\text { certain actions (save), including } \\
\text { actions not scripted in the IVR } \\
\text { messages (borrow a loan). }\end{array}$ & $\begin{array}{l}\text { - Save } \\
\text { - Borrow a loan }\end{array}$ & $\begin{array}{l}\text { - "She remembers the } \\
\text { calls, that Alice would } \\
\text { say you should save" - } \\
\text { Staff } \\
\text { - "Most of the clients } \\
\text { come to the branch say- } \\
\text { ing that Sister Alice said } \\
\text { they should come for a } \\
\text { loan. It puts us, the offic- } \\
\text { ers, under pressure to ex- } \\
\text { plain." - Staff }\end{array}$ \\
\hline $\begin{array}{l}\text { 7. Alice as Gendered (Mysterious } \\
\text { Female Caller/ Homewrecker, } \\
\text { etc.) } \\
\text { Clients and staff used gendered } \\
\text { language (i.e., "she," "her") } \\
\text { when speaking about the IVR } \\
\text { calls. In some cases, the gendered } \\
\text { aspect of Alice generated conse- } \\
\text { quential effects. According to } \\
\text { staff, clients mentioned cases of } \\
\text { household conflict related to Al- } \\
\text { ice: women confronted their male } \\
\text { partner out of curiosity or with the } \\
\text { belief that their partner was ro- } \\
\text { mantically involved with "Alice." }\end{array}$ & $\begin{array}{l}\text { - Husband ac- } \\
\text { cused of } \\
\text { cheating on } \\
\text { wife } \\
\text { - Wife curious } \\
\text { - "Sister Alice" }\end{array}$ & $\begin{array}{l}\text { - "The wife was suspect- } \\
\text { ing him of cheating be- } \\
\text { cause someone called Al- } \\
\text { ice has been calling } \\
\text { him." - Staff } \\
\text { " "One client commented } \\
\text { that the wife picked [up] } \\
\text { the call and was curious } \\
\text { who Alice is." - Staff }\end{array}$ \\
\hline
\end{tabular}




\subsection{Technical Aspects}

The Alice effect was made possible by various sociopsychological and physical elements. Within the scope of our study, we focused on the role of technology within the human-machine interaction which gave rise to anthropomorphic perceptions of "Alice." Hence our analysis presents technical explanations for how the "Alice effect" was made possible.

Based on our investigation of the socio-technical relationship between users and the IVR system, we found that the Alice effect was enabled through various features and configurations of the technology. Through an analytical interweaving of interview and observational data, we drew connections among various technological aspects and anthropomorphic perceptions of "Alice." By applying affordances as a conceptual lens, we identified several technology affordances which we found to culminate in four main ways that helped explained how the IVR system helped facilitate anthropomorphic perceptions among users. The following table presents a summary of our findings.

Table 2. Summary of technical aspects that contributed to the Alice effect

\begin{tabular}{|c|c|c|}
\hline & Underpinning affordances & $\begin{array}{l}\text { Embedded human-like } \\
\text { elements }\end{array}$ \\
\hline $\begin{array}{l}\text { 1. Capture, Storage and } \\
\text { Renderings of Voice } \\
\text { Recordings }\end{array}$ & $\begin{array}{l}\text { Capability to capture and store hu- } \\
\text { man voice as audio clips } \\
\text { Capacity to integrate and combine } \\
\text { audio clips } \\
\text { Capacity to rapidly introduce, com- } \\
\text { bine and rearrange audio clips }\end{array}$ & $\begin{array}{l}\text { Human voice messages } \\
\text { Tailored messages } \\
\text { Two-way conversation for- } \\
\text { mat }\end{array}$ \\
\hline $\begin{array}{l}\text { 2. Mimicry of Human- } \\
\text { like Conversation } \\
\text { Methods }\end{array}$ & $\begin{array}{l}\text { Capacity to integrate IVR and mo- } \\
\text { bile network operator systems to de- } \\
\text { liver phone calls } \\
\text { Capability to transfer patterns of } \\
\text { sound waves from human speech } \\
\text { into electronic impulses [30] }\end{array}$ & Phone calls \\
\hline $\begin{array}{l}\text { 3. Mimicry of Human- } \\
\text { like Conversational Ele- } \\
\text { ments }\end{array}$ & $\begin{array}{l}\text { Capability to capture, store, and in- } \\
\text { tegrate human voice }\end{array}$ & $\begin{array}{l}\text { Prosodic features of human } \\
\text { speech (intonation, stress, } \\
\text { tone, and rhythm) } \\
\text { Gendered }\end{array}$ \\
\hline $\begin{array}{l}\text { 4. Presentation of } \mathrm{Hu}- \\
\text { man-like Message Con- } \\
\text { tent }\end{array}$ & $\begin{array}{l}\text { Capacity to send calls on a pre-pro- } \\
\text { grammed schedule } \\
\text { Capacity to pre-program audio re- } \\
\text { sponses following customer input } \\
\text { Capacity to capture, store, and apply } \\
\text { customer call data } \\
\text { Capacity to integrate customer sav- } \\
\text { ings data from core banking system }\end{array}$ & $\begin{array}{l}\text { Informational, interactive, } \\
\text { culturally relevant, and af- } \\
\text { fect-laden message content }\end{array}$ \\
\hline
\end{tabular}


Capability to solicit customer input

and interaction via mobile phone

connectivity

1. Capture, Storage and Renderings of Voice Recordings. The IVR system used prerecorded voice messages which were stored on hundreds of short audio clips. The audio clips could be manipulated and edited by the project team to configure the messages to the intended users (listeners). The IVR technology possessed the capacity to rapidly introduce, combine and rearrange audio clips. The audio clips could be sliced and rearranged to render variations in the sequencing of the audio clips and to develop premade voice-loops. The ability to rapidly manipulate the recordings enabled the project team to develop messages in an iterative fashion, while the ability to set pre-made voice-loops enabled clients to re-listen to messages and to select alternative messages from a menu of options. These technology affordances can therefore be summarized as enabling the common human-like elements: human voice messages, tailored messages and the format of a two-way conversation.

2. Mimicry of Human-like Conversation Methods. For IVR messages to be delivered by phone to users, the technology was integrated with the system of one of the largest mobile network operators in the country. The seamless integration made the IVR calls indistinguishable from human-delivered calls based on the calls' method of delivery. Phone calls are human-machine interactions which rely on telephone systems that transfer patterns of sound waves from human speech into electronic impulses [30]. With over a hundred years in existence, telephony has become readily available and is easily understood (ibid). In our case, phone calls were already a familiar medium of humanto-human communication for users hence receiving the IVR messages as a phone call presented a human-like element.

3. Mimicry of Human-like Conversational Elements. Mimicking human-like conversation was enacted through various conversational elements such as style and approach. The voice recordings contained human patterns of speech. By using voice actors for the recordings instead of machine-generated voice synthetization, the IVR system was able to model human speech without various limitations faced by some textto-speech systems. For instance, the voice actors naturally conveyed prosodic features of human speech such as intonation, stress, tone, and rhythm. The message scripts included instructions for the voice actors through punctuation (i.e., full stops, question and exclamation marks) and special notations (i.e. a " $<$ pause $>$ " to signal when a longer break between sentences was necessary).

Another characteristic of human-like conversation found in the data was the gendered nature of the technology due of the use of a female voice and the named character "Alice." In the interview data, clients and staff referred to the caller as "Alice" and "she" as opposed to "the machine" or "it." This provided additional evidence for the phenomenon of anthropomorphism. 
These technology affordances- from the voice recordings and the integration of these recordings- can therefore be summarized as enabling the human-like elements of gender and various prosodic features of human speech.

4. Presentation of Human-like Message Content. The IVR system also modeled human-like conversation through the message content which was substantively informational, interactive, culturally relevant, and affect-laden.

The IVR messages provided various types of information which by nature would typically be provided to clients by bank staff. Some of the information came as push communications, meaning that the content was programmed to provide information according to a predetermined call schedule. Other information was availed by the users through their interaction with the system. Users could use the keypad of their mobile phone to interact with the system such as by dialing a number that corresponded to a number on a menu. For instance, "Alice" might pose a question such as, "Use your mobile handset to tell us if you have set a savings goal for you or your family. Press 1 if you have a savings goal. Press 2 if you don't have a saving goal and want some help with setting one." Responses from "Alice" could take into consideration user-generated content or other sourced information (i.e., bank account information from the core banking system). This question and answer format might feel familiar and human-like to the user, while the input method for responses might feel unfamiliar and machinelike. It is the familiar elements which help the user adapt to the unfamiliar aspects of the technology [6].

The voice messages were designed to contain cultural and emotional relevancy. Because the IVR messages were typically short - less than 1 minute per message - the language used in each message was carefully selected and often relied on short soundbites commonly known or associated with local knowledge. "Alice" started each call with an introduction and greeting which modeled human phone conversation etiquette. One client commented, "Whenever Alice calls, she greets me." Furthermore, some of the messages contained cultural expressions and idioms which helped convey specific meanings using a concise format.

Additional evidence for anthropomorphism came from user language which attributed "Alice" as having carried out certain actions, such as calling, talking, asking questions, and watching them save. Some clients even reported that "Alice" behaved in ways that went beyond the limitations of the IVR system. For instance, some clients described "Alice" as responding to their individual needs, such as calling to follow-up on specific challenges they faced and to ask questions about their specific businesses. Although such personalized interactions were technically infeasible, these findings suggest that an emotional connection with "Alice" was present in some of the users' experiences of anthropomorphism. "Alice" represented a staff member of ABC company for which human relationships between clients and bank staff had been the norm [30]. 


\section{Discussion and Implications}

In addressing our research question on how an IVR technology exhibits human-like qualities within the user-technology interaction, our findings highlight various technical aspects that contributed to anthropomorphism in the case of ABC company. Using an affordance lens, we identified four main ways that the IVR system helped facilitate anthropomorphic perceptions among users. In this section, we consider the significance of anthropomorphism for IS scholarship and practice based on our findings.

\subsection{Contributions to the IS Affordance Literature}

Anthropomorphism, a phenomenon that has historically involved attributing humanlike qualities to a vast array of living and non-living subjects, has become increasingly relevant for IS especially due to the growing popularity of robotics and conversational agents. As more cases of anthropomorphism are situated in socio-technical relationships, the field of IS becomes particularly important for shedding light on the technological processes which underpin anthropomorphism. As demonstrated by our research, an affordance lens enables a rigorous methodological study of various technical aspects which underpin anthropomorphic perceptions. This conceptual lens, as we have shown, offers an improved understanding of the role of technology in anthropomorphism.

The IS affordance literature has focused largely on cognitive perceptions, particularly actor intentions, to explain the relationship between technology and affordance actualization (action). This research expands the ways of theorizing affordance perception by highlighting the roles of imagination and affect (emotion) for trigging affordance actualization. As demonstrated by our research, technology affordances can work together to evoke users' imaginations and emotions, fostering anthropomorphic perceptions and outcomes. Building on the work of Nagy and Neff (2015), who underscored the importance of the imagination in affordances, this research highlights how the development of technical anthropomorphism [7] occurs within a socio-technical relationship between technologies and user perceptions, imagination, and affect.

\subsection{Anthropomorphism's Role in Technology Adoption and Diffusion}

Anthropomorphism is important for IS because of the significant role it can play in the adoption and diffusion of technology. According to Pfeuffer et al. (2019) and Sims et al. (2005), anthropomorphism helps users in their adoption of technology. This is because machines can be designed to provide contextually sensitive and seemingly accurate responses which makes the interactions seem more natural and human-like [6]. As found in our analysis, the IVR system contained human-like components which were familiar to users and helped users in their adoption of IVR as a new communications channel at ABC Company.

Understanding the technical aspects underpinning anthropomorphism is important because it can lead to improved business practices. Anthropomorphic design of technologies can help facilitate ease of use in the user experience by bridging the gap between human familiarity and technological unfamiliarity. The phenomenon of 
anthropomorphism is situated within the socio-technical relationship and can be coproduced by users and systems managers. Anthropomorphic perceptions, imaginations, and affect among users can be cultivated by systems managers through the configuring and reconfiguring of anthropomorphic design. Through our affordance study, we offer practical implications for identifying and developing anthropomorphic design features which can positively impact technology adoption and diffusion.

\subsection{The Anthropomorphic Outcome of Relationship Building}

Along with helping users bridge a technical knowledge gap, anthropomorphic design can help bridge relational gaps through human affect. Technology companies such as Apple and Google have found that anthropomorphic design features have helped foster social connections and built trust among users [6]. Evidence was found in our case that the human-like elements of the IVR calls helped build the client-institution relationship. When asked how clients felt about ABC Company after getting the IVR messages, many clients expressed a sense of feeling closer to the organization. One client responded, "Good. I feel well connected. Anytime I saw the call, I will $<$ be $>$ like 'eei my people'." Another client responded, "I realized that you think about your customers and that really touched my heart." Based on our analysis, client-institution relationship building took place directly (i.e., with clients perceiving "Alice" as a person with whom they form a relationship) and indirectly (i.e., with clients prompted by the IVR calls to connect with the institution such as by visiting a bank branch). These findings provide implications for how relational value might be generated, cultivated, or otherwise affected by technology artefacts when these artefacts are configured to embed humanlike qualities.

\section{Conclusion}

Through this case study on anthropomorphism and an enfolding of the literature [31], we have demonstrated how technologies can have consequential outcomes. By decomposing anthropomorphism from an affordance perspective, we have demonstrated how affordance theory can help shed light on the technological processes that underpin anthropomorphism. By bringing to the forefront various technical aspects which helped generate (perceivable) human-like elements, we have provided an improved understanding of the role of technology in anthropomorphism.

This research generates new insights into the utility of affordance theory and expands the IS affordance literature by highlighting the roles of imagination and affect for triggering affordance actualization. It also provides a methodological roadmap for other scholars wishing to investigate the relationship between technology affordances and anthropomorphism. These contributions to the IS affordance literature provide an entry point for the topic of anthropomorphism. It is our hope that future research will uncover many more insights on the relationship between technology affordances and anthropomorphism. 


\section{References}

1. Pozzi, G., Pigni, F. \& Vitari, C. Affordance Theory in the IS Discipline : a Review and Synthesis of the Literature. (2017).

2. Schuetzler, R. M., Giboney, J. S., Grimes, G. M. \& Nunamaker, J. F. The influence of conversational agent embodiment and conversational relevance on socially desirable responding. Decis. Support Syst. 114, 94-102 (2018).

3. Freud, S. Civilization and its Discontents. (Norton, 1930).

4. Epley, N., Waytz, A. \& Cacioppo, J. On seeing human: a three- factor theory of anthropomorphism. Psychol Rev 114, 864-886 (2007).

5. Urquiza-Haas, E. G. \& Kotrschal, K. The mind behind anthropomorphic thinking: Attribution of mental states to other species. Anim. Behav. 109, 167-176 (2015).

6. Pfeuffer, N., Benlian, A., Gimpel, H. \& Hinz, O. Anthropomorphic Information Systems. Bus. Inf. Syst. Eng. 61, 523-533 (2019).

7. Tondu, B. Anthropomorphism and service humanoid robots: An ambiguous relationship. Ind. Rob. 39, 609-618 (2012).

8. Iossifidis, I., Theis, C., Grote, C., Faubel, C. \& Schoner, G. Anthropomorphism as a pervasive design concept for a robotic assistant. 3465-3472 (2004). doi:10.1109/iros.2003.1249692

9. Taddeucci, D. et al. Model and implementation of an anthropomorphic system for sensory-motor perception. 1962-1967 (2002). doi:10.1109/iros.1998.724890

10. Hashimoto, S. et al. Humanoid robot-development of an information assistant robot Hadaly. 106-111 (2002). doi:10.1109/roman.1997.646961

11. Sims, V. K. et al. Anthropomorphism of Robotic Forms: A Response to Affordances? Proc. Hum. Factors Ergon. Soc. 49th Annu. Meet. 1922-1926 (2005).

12. Gibson, J. J. (James J. The ecological approach to visual perception. (Houghton Mifflin, 1979).

13. Gibson, J. J. The Ecological Approach to Visual Perception. (Psychology Press, 1986).

14. Markus, M. L. \& Silver, M. S. A foundation for the study of IT effects: A new look at DeSanctis and Poole's concepts of structural features and spirit. J. Assoc. Inf. Syst. 9, 609 (2008).

15. Leonardi, P. M. When Flexible Routines Meet Flexible Technologies: Affordance, Constraint, and the Imbrication of Human and Material Agencies. (Social Science Research Network, 2011).

16. Anderson, C. \& Robey, D. Affordance potency: Explaining the actualization of technology affordances. Inf. Organ. 27, 100-115 (2017).

17. Leonardi, P. M. When does technology use enable network change in organizations? A comparative study of feature use and shared affordances. MIS Q. 37, 749-775 (2013).

18. Yoo, Y., Boland, R. J., Lyytinen, K. \& Majchrzak, A. Organizing for Innovation in the Digitized World. Organ. Sci. 23, 1398-1408 (2012).

19. Majchrzak, A. \& Markus, M. L. Technology Affordances and Constraints in Management Information Systems (Mis). in Encyclopedia of Management Theory 5 (Social Science Research Network, 2012). doi:http://dx.doi.org/10.4135/9781452276090.n256

20. Majchrzak, A., Markus, M. L. \& Wareham, J. Designing for digital transformation: lessons for information systems research from the study of ICT and societal challenges. 
Manag. Inf. Syst. mis Q. 40, (2016).

21. Robey, D., Anderson, C. \& Raymond, B. Information Technology, Materiality, and Organizational Change: A Professional Odyssey. J. Assoc. Inf. Syst. 14, (2013).

22. Seidel, S., Recker, J. \& Brocke, J. vom. Sensemaking and Sustainable Practicing: Functional Affordances of Information Systems in Green Transformations. Manag. Inf. Syst. Q. 37, 1275-1299 (2013).

23. Volkoff, O. \& Strong, D. M. Critical Realism and Affordances: Theorizing IT-Associated Organizational Change Processes. MISQ 37, 819-834 (2013).

24. Strong, D. et al. A Theory of Organization-EHR Affordance Actualization. J. Assoc. Inf. Syst. 15, 53-85 (2014).

25. Stendal, K., Thapa, D. \& Lanamaki, A. Analyzing the concept of affordances in information systems. Proc. Annu. Hawaii Int. Conf. Syst. Sci. 2016-March, 5270-5277 (2016).

26. Nagy, P. \& Neff, G. Imagined Affordance: Reconstructing a Keyword for Communication Theory. Soc. Media Soc. 1, (2015).

27. Kardes, F., Cronley, M. \& Cline, T. Consumer Behavior. (Cengage Learning, 2015).

28. Miles, M. B. \& Huberman, A. M. Qualitative Data Analysis : an Expanded Sourcebook. (Sage Publications, 1994).

29. Yin, R. K. Case study research: design and methods. (Sage Publications, 2003).

30. Liebenau, J. \& Backhouse, J. Understanding Information: An Introduction. (Palgrave, 1990).

31. Eisenhardt, K. M. Building Theories from Case Study Research. Acad. Manag. Rev. 14, 532-550 (1989). 